\title{
Resolving the conundrum of superior performers in organizations with the utilization of competency profiling
}

\author{
Nornazira Suhairom ${ }^{1, *}$, Nur Husna Abd Wahid ${ }^{1}$, Rafeizah Zulkifli ${ }^{1}$ and Ahmad Nabil Md \\ Nasir ${ }^{1}$ \\ ${ }^{1}$ School of Education, Faculty of Social Science \& Humanities, Universiti Teknologi Malaysia, 81310 \\ Johor, Malaysia
}

\begin{abstract}
Studies have shown that superior performers provide increased productivity, profit and revenue especially for service and business-driven organizations. Undeniably, good people are great for business; however, previous studies provide limited indication on how to identify superior performers from average performers. In this study, the Star-Chef Competency Profile Assessment test was developed to help organizations identify and differentiate superior performers. The instrument helps in identifying and articulating the distinguishing characteristics of people who perform exceptionally well compared to those that do not. The Star-Chef Competency Profile Assessment analyses a person's fit with six pillars of competency that encompass important competencies required for culinary profession: technical (culinary-specific), non-technical (generic), selfconcept, personal quality, physical state and motives. Further, the competency profiling technique utilized the Rasch Measurement Model in identifying the superior performers. Competency profiling assessment was conducted among culinary professionals in Malaysian hotels sector. This is a practical, unique approach in improving organizational talent management practices for employee training and development. Identifying and keeping the superior performers is important in enhancing work performance outcome which eventually will contribute to the organizational effectiveness. This information hones the organization ability to nail down the best employees that could be polished for higher level.
\end{abstract}

\section{Introduction}

Since 2008, Malaysian government has embarked on important missions to increase the number of high-skilled workers in the industry. As in 2010, there are 6638 recognized and accredited institutions which are responsible for MSOQ (Malaysia Occupational Skills Qualifications) training programmes. Data from Table 1 shows the certification status for MOSQ according to each level since 1994, the year where the qualification systems started being introduced until 2009. The numbers of certifications are progressing from years to

* Corresponding author: p-nazira@utm.my 
years though it fluctuates a bit. However, there is a huge gap in the number of certification according to each level which is 87 percent for Low Levels (Level 1 and 2) and only 13 percent for High Levels (Level 3 to 5) (Department of Skills Development, 2013). To date, any regulatory approaches to continuing competence as well as professional licensure for chef's profession in Malaysia are not available.

Table 1. Statistic of Malaysia occupational skills qualification (1994-2009)

\begin{tabular}{|c|c|c|c|c|c|c|}
\hline \multirow{2}{*}{ YEAR } & \multicolumn{6}{|c|}{ NUMBER OF CERTIFICATIONS } \\
\cline { 2 - 6 } & \multicolumn{2}{|c|}{ Low Level } & \multicolumn{3}{c|}{ High Level } & \multirow{2}{*}{ TOTAL } \\
\cline { 2 - 6 } & 1 & 2 & 3 & 4 & 5 & \\
\hline 1994 & 556 & 42 & 0 & 0 & 0 & 598 \\
\hline 1995 & 1550 & 278 & 0 & 0 & 0 & 1828 \\
\hline 1996 & 2864 & 1291 & 7 & 0 & 0 & 4162 \\
\hline 1997 & 7390 & 2362 & 207 & 0 & 0 & 9959 \\
\hline 1999 & 8140 & 4169 & 537 & 1 & 1 & 12848 \\
\hline 2000 & 13751 & 8771 & 1844 & 1 & 0 & 24367 \\
\hline 2001 & 18185 & 22504 & 7441 & 2 & 2 & 46128 \\
\hline 2002 & 26495 & 19583 & 2857 & 2 & 0 & 48937 \\
\hline 2003 & 53526 & 50649 & 9550 & 0 & 0 & 113725 \\
\hline 2004 & 36998 & 41508 & 12939 & 985 & 0 & 92430 \\
\hline 2005 & 43190 & 39819 & 16259 & 1469 & 5 & 100742 \\
\hline 2006 & 40108 & 33652 & 8932 & 2322 & 11 & 85026 \\
\hline 2007 & 42203 & 33402 & 10049 & 2942 & 16 & 88612 \\
\hline 2008 & 49091 & 40905 & 11776 & 2440 & 32 & 104244 \\
\hline 2009 & 42262 & 35098 & 12722 & 1376 & 68 & 104244 \\
\hline TOTAL & 405951 & 355636 & 100003 & 11540 & 135 & 91526 \\
\cline { 2 - 6 } & $761587 \mathbf{( 8 7 \% )}$ & & $111678(\mathbf{1 3 \%})$ & 873265 (100\%) \\
\hline
\end{tabular}

(Source: Ministry of Human Resource, 2010)

In Malaysian context, culinary profession is observed as one profession that is laborintensive and dynamic in the diversified career market. Views related to the importance of culinary as one of the most demanding professions in the Malaysian hospitality and tourism were shared by Hamed, Wahab, Zakaria, \& Jasmi [44]. Culinary tourism creates vast job opportunities for young generations and thus, reducing the rate of unemployment. Furthermore, a study by Mokhtar, Poo \& Salleh [30] revealed that employment demand for 2015 manpower from sub-sectors hotels and restaurants in Malaysian tourism sector shows a significant impressive improvement. This clearly shows that the industry provides promising future career undertakings as positive employment prospects in these sub-sectors are expected in the near future.

The broader discourse of competency issues was immensely discussed in the realm of culinary world. Although culinary professionals' role in the emergence of food tourism is 
considered greatly significant and approached in literature [45], there is ambiguity that has yet to be conferred. Current changes in the Malaysian hospitality and food tourism market have impacted the requirements and the tasks to be performed by workforce in the industry [37]. Culinary cadres are required to master wide range of competencies in order to remain relevant in the industry. Research in the area of culinary profession is scarce, and so as the research in identifying competencies required for the culinary professionals' superior work performance. Several studies related to chef's competencies were conducted in other countries such as in Cyprus [45], Costa Rica [1], Hong Kong (Hu, 2010; 26], United Kingdom (Bisset, Cheng \& Brannan, 2010) and United States [10,11] which provides a preliminary views on what is expected from the culinary professions globally.

Identification of superior performers through competency profiling is useful where the organization will be able to map the worker's competency in identifying potential superior performers. Nevertheless, currently there is a limited indication on a specific mechanism in identifying the competencies possessed by existing professionals in the industry. Thus, this study provides insights that using a well-developed competency measurement instrument, employees' competency could be measured. Eventually, a competency profiling which emphasized on the mastery level of culinary professionals could be developed. The findings will contributes in generating relevant data that could be used to guide improvement interventions in the industry. In line with the recommendations by Orr, Sneltjes and Dai [32], competency profiling is one of the best practices for selecting, developing and deploying talents. The results from the competency measurement using the Star-Chef Competency Profile Assessment test, where applicable, could help the human resource management in identifying areas of professional development that necessitates for attentions. The current study seeks to answer the following research question:

To develop a competency profile for culinary professionals based on the SC-SAT Competency Measurement Scale.

\section{Literature Review}

\subsection{Competency Model as Guidance of Individual Behavior at Workplace}

Organizational quality is much dependent on the quality of the workforce [28] as well as the identification of critical needs and resources for the changing workplace (Society of Human Resource Management, 2008). These two aspects are important for todays' contemporary hospitality and tourism industry. The industry are labor intensive, employing a wide variety of individuals, each having a unique experience, skills sets, and motivational pattern. Thus, the challenge for the human resource management is to manage the human capital in effective manner so that individual performance can be well-managed [18]. According to Koopmans [27] and Viswesvaran [39], individual performance is determined by the person's skills and capabilities. Research which emphasizes into individual performance in organizations is important in order to provide better understanding of the managerial and economic proficiency among individuals in the profession.

Theory and research note the prominence of competencies for individual work performance. For an individual to perform the best at workplace, they need to have a synergy of competencies along with experience in delivering job task on any given day, even on any given circumstances [42]. Competencies can be gathered through education, training or experience. Experience is the duration of life within work. Nevertheless, to learn a lesson from experience gained at the workplace also requires certain amount of competency $[3,4]$. In line with these ways of competency acquisition is the behavior 
(understanding of the consequences of the action taken and having the right attitude towards work performance).

Several researchers $[29,40]$ agree that competency model is a model that provides a list of competency statement that is necessary for effective job performance. Specifically, competency model consists of a combination of individual competencies that represents competency required for employees' superior performance and success in the profession. In the realm of culinary, competency frameworks and models has been developed and applied in various hospitality settings especially in the hotels and restaurants. Studies show that competency model has been used widely in the hospitality, tourism and culinary industry [23, 24, Cheng, 2012). For instance, several competency models have been developed in hospitality management that focuses on the leadership and management competencies of hotel and restaurant managers $[14,25]$. In more specific culinary research area, there are a number of studies that present chef's competency studies [11, 12, 45].

\subsection{Competency Profiling for Culinary Professionals}

Workers in the industry need to stay relevant with the latest trends and progress in the industry, or else their knowledge and skills might become obsolete. For instance, retraining and skills upgrading is one way which of paramount importance to enhance the quality of workforce so that it is versatile and adaptable to the changing technological and business environment (Human Resources Development Fund Malaysia, 2013). Recently, there have been growing interests of research studies aiming at distinguishing the characteristics of exemplary employees in the industry. High performer is an employee who is a key contributor, demonstrates high performance, is capable of a lateral move, may be qualified for a broader role within the same profession and has reached the potential to move "upward" in a management capacity [15].

According to Azrilah, et al., [6], competency profiling refers to a model which comprises competency attributes required by the employees. Competency profiling is the process of finding out the skills that are needed to do the job effectively. In organizations, the competency profiling provides an opportunity for the upper level management executives to identify competencies that are important for professional training and development. Researchers has agreed that the development of competency profiles will benefit organizations in efficaciously define and identified employees' competencies that can then utilized as performance benchmarking [31]. It is important to build competency profiles in order to assist the human resource management of organizations in the recruitment process. Furthermore, for personal utilization, the competency profiles may benefits individual worker in identifying their own strengths and weaknesses. With adequate and sufficient resources, employees will be able to perform their job well.

\section{Methodology}

\subsection{Design}

A cross-sectional survey was conducted among culinary professionals. Two-stage of instrument development testing was carried out among culinary professionals working at 4and 5-starred hotels in Malaysia. 


\subsection{Sample}

The instrument was tested on two groups of culinary professionals, representing two Instrument Testing stages (Instrument Testing I, $n=35$ and Instrument Testing II, $n=42$ ). The study involved culinary professionals in 4-star and 5-star hotels in Peninsular Malaysia.

\subsection{Instrument}

The Star-Chef Competency Profile Assessment test was used to gather information about competency. The first instrument testing was conducted among 35 culinary professionals in 4-star and 5-star hotels which involved an analysis of 203 items measuring six constructs (technical, Non-technical, Personal Qualities, Self-concept ad Motives).

\subsection{Data Analysis}

The collected data were analyzed using SPSS 24.0 and Winstep software. The first stage of data analysis mainly focused on the psychometric analysis of the SCSAT Competency Scale. In this study, Rasch measurement model is the basis of analysis in identifying the reliability and validity of the instrument. The purpose of each instrument testing is to examine the reliability and generate empirical evidence to support the validity of the instrument in eight areas of Rasch diagnoses: (i) item and person separation and reliability coefficients (ii) item polarity (iii) item fit (iv) person abilities fit (v) value of standardized residual variance (vi) scale category function (vii) unidimensionality of the constructs and (viii) level of items difficulties and person response. Consequently, the data which analyzed using Rasch analysis were utilized to develop the competency profile of the culinary professionals based on the SC-SAT instrument. The item strata were utilized in the study. To construct strata in identifying the performance level of the culinary professionals, the formula used is

$$
\text { Number of Person or Item Strata, } H=\frac{4 \mathrm{G}+1}{3}
$$

where $\mathrm{G}$ is the separation index of item or person

The strata are defined as statistically distinct measures as suggested by Fisher [17] and Wright \& Masters [43]. By this means, the level of competencies among culinary professionals could be classified into several categories based on their responses in the SCSAT instrument.

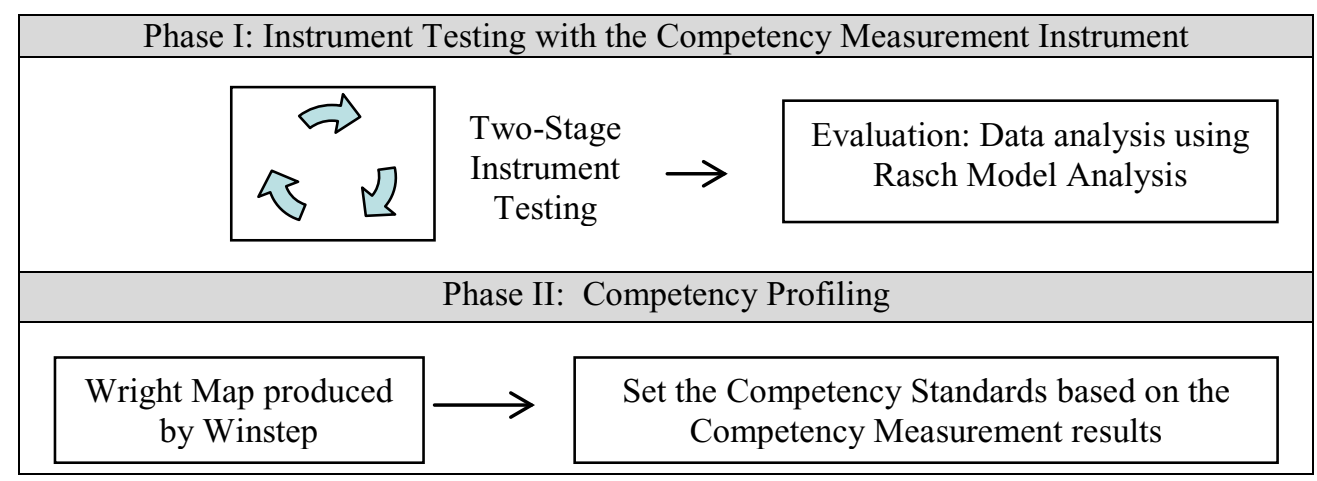

Fig. 1. Operational research framework 


\section{Findings}

The aim of this competency profiling is to describe the useful information related to the culinary professionals whom involved in the study $(\mathrm{n}=35)$ in Instrument Testing I and $(\mathrm{n}=42)$ in Instrument Testing II.

\subsection{Instrument Testing 1}

The performance of the respondents in answering the SC-SAT items was examined. The SC-SAT yield an item reliability of 0.80 , item separation of 2.01 and person reliability of 0.99 , person separation of 9.97 . In this study, the performance of the culinary professionals is based on their ability to perform task in SC-SAT instrument. Thus, the item strata were utilized. To construct the strata in identifying the performance level of the culinary professionals, the formula used is

Number of Person/ Item Strata, $\mathrm{H}=\frac{4 \mathrm{G}+1}{3}$ where $\mathrm{G}$ is the separation index

The item strata is $[4(2.01)+1] / 3=3.01$. This means the performance towards SC-SAT instrument can be separated into 3 levels, which are High, Mediocre and Low (Omar, Rodzo'an, Saidfudin, Zaharim \& Basri, 2010). Previously, the competencies were categorized into threshold (T) and differentiating (D) competency by the subject-matter experts during the Content Validity Procedure (CVR) process. The experts identified 36 sub constructs as differentiating and 8 sub constructs as threshold. Based on these categories, there are 156 differentiating items. Experts also agree that $90 \%$ mastery of the differentiating competency is required for a superior work performance in culinary profession. With an expectation of $90 \%$ mastery of the differentiating competencies, there are 140 items to be put into attention. The 156 differentiating items were divided into 3 performance levels, resulting 52 differentiating items in each performance levels. As shown in Table 2, the item measure is summed up and divided by the number of items in each group, thus establishing the mean of item measure as cutscore for the respective performance levels.

Table 2. Indicators of performance levels: Instrument testing I

\begin{tabular}{|l|l|c|c|c|}
\hline Group & Item Measure (logit) & $\begin{array}{c}\text { No of } \\
\text { items }\end{array}$ & $\begin{array}{c}\text { Mean } \\
\text { (logit) }\end{array}$ & $\begin{array}{c}\text { Standard } \\
\text { Error (SE) }\end{array}$ \\
\hline Group 1 (High) & COGN3 (+0.44) to SCI3 (+1.21) & 54 & +0.72 & 0.23 \\
\hline Group 2 (Mediocre) & CAR15 (-0.15) to ENTR6 (+0.44) & 70 & +0.10 & 0.25 \\
\hline Group 3 (Low) & SOCI6 (-1.82) to CAR18 (-0.15) & 79 & -0.60 & 0.27 \\
\hline Total items & & 203 & & \\
\hline
\end{tabular}

Table 3(Appendix) demonstrates the Item Measure for the first instrument testing. Based on the list, the cut-scores for performance levels were identified. The expected $90 \%$ of competency mastery level of 140 items is identified and bookmarked at item CRE4 (Ability to make products with vitality) with measure of +0.86 logit. Rasch analysis has indeed made the evaluation more objectively and produce the demarcation line in a very clear graphical presentation which is easy to read and easier to understand. This enable thorough analysis of the grading pattern according to performance level.

The established demarcation lines is superimposed on the Person Measure Order Table as shown in Figure 2 (Appendix). The expected 'mastery' level of $90 \%$ agreed at 0.86 logit located at the High Performance level. Previously, there are three performance levels that were identified. However, upon reviewing the findings, the High Performance level 
could be divided into one more group, which is the Superior Performance level. Thus, it can be identified that $20 \%$ of these 35 culinary professionals are superior performers (seven culinary professionals). From the figure, it can be seen that there are two person from the High Performance group level who perform below the $90 \%$ of mastery which are person S11 and A30. There are 46\% culinary professionals categorized in the High Performance level, $23 \%$ in Mediocre Performance and $11 \%$ in Low Performance level. These findings show that superior, high, mediocre and low performers can be observed in the actual assessment process.

\subsection{Instrument Testing 2}

For the second instrument testing, the profiling was developed based on the data from the performance of 42 culinary professionals towards the SC-SAT instrument. The SC-SAT instrument yield item reliability is 0.91 with separation index of 3.21 and person reliability 0.98 with separation index of 8.01 . The calculated item strata is $[4(3.21)+1] / 3=4.61$. Thus, the performance towards SC-SAT instrument in Instrument Testing II can be separated into 5 levels, which are Very High, High, Mediocre, Low and Very Low. Again, the experts evaluation on threshold and differentiating competencies were referred. Based on the identified 36 differentiating competency and 8 threshold competency, there are 130 differentiating items and 34 threshold items. With an expectation of $90 \%$ mastery of differentiating competencies, there are 117 items that need to be put into attention. The 130 differentiating items were divided into 5 performance levels, resulting 26 differentiating items in each performance levels. In each level, the item measure is summed up and divided by the number of items in each group to establish the mean of item measure (in logits) and cutscore for the respective performance levels. Table 3 showed the details regarding the indicators of performance levels.

Table 3. Indicators of performance levels: Instrument testing II

\begin{tabular}{|l|l|l|l|l|}
\hline Group & Item Measure (logit) & $\begin{array}{l}\text { No of } \\
\text { items }\end{array}$ & $\begin{array}{l}\text { Mean } \\
\text { (logit) }\end{array}$ & $\begin{array}{l}\text { Standard } \\
\text { Error (SE) }\end{array}$ \\
\hline Group 1 (Very High) & CRE4 (+0.88) to SCI2 (+2.59) & 26 & 1.34 & 0.23 \\
\hline Group 2 (High) & EST3 (+0.30) to RES1 (+0.88) & 31 & 0.58 & 0.23 \\
\hline Group 3 (Mediocre) & SAF4 (-0.23) to FIN3 (+0.30) & 38 & 0.04 & 0.23 \\
\hline Group 4 (Low) & LEA2 (-0.62) to CAR14 (-0.23) & 30 & -0.12 & 0.24 \\
\hline Group 5 (Very Low) & OPS7 (-1.79) to CAR6 (-0.62) & 39 & -1.06 & 0.25 \\
\hline Total items & & 164 & & \\
\hline
\end{tabular}

Table 5 (Appendix) demonstrates the Item Measure for the first instrument testing. Based on the list, the cut-scores for performance levels were identified. The expected $90 \%$ of competency mastery level of 117 items is identified and bookmarked at item SCI4 (I know the purpose of using food additives in foods preparation) with measure of +1.23 logit. With this Rasch analysis, the demarcation lines were produced and thus, enabled a thorough analysis of the grading pattern according to performance level. The established demarcation lines are superimposed on the Person Measure Order Table as shown in Figure 3 (Appendix). The expected 'mastery' level of $90 \%$ was agreed at +1.23 logit located at the High Performance level. Previously, there are five performance levels that were identified. Upon reviewing the findings, there is no culinary professionals who falls within the Very Low performance level. There is only one person in the Low performance level (3\%), six person in Mediocre performance level (14\%) and eight person in High performance level $(20 \%)$. Majority of the culinary professionals are classified into the Very High performance level $(46 \%)$. However it can be identified from the figure that there are seven 
Superior performers, those who perform beyond one Standard Deviation above the Mean (exceeding logit +2.70 ).

\section{Discussions}

In this section, the researcher discusses on the competency profiling among culinary professionals, which were generated from the Rasch analysis. One advantage of item response theory analysis is that both estimates can be arranged on the same scale and easily compared. The item-person-map for each model visualizes the item difficulties on the right, by ordering them from more difficult (top) to less difficult (bottom), and the latent trait levels on the left (grouping persons with the same values together). Ideally, the item difficulties should be well dispersed around the mean, having the most items in the medium difficulty range, but also providing items with high and low difficulties. Additionally, the latent traits are separated by dimension. The current study examines the high performer's competency profiles of culinary professionals in Malaysian hotels setting. Two-stage of instrument testing were conducted to yield data on workforce competencies. Thirty-five responses from Instrument Testing I and forty-two responses from Instrument Testing II to the SCSAT Competency Scale were used to profile the competencies. There are six competency elements, which are technical, non-technical, personal quality, self-concept, physical state, and motives of culinary professionals who work in the 4- and 5-starred rated hotels. The competency profiling from each instrument testing shows that majority of the culinary professionals have a high mastery level of competencies in culinary. This study indicates that our Malaysian culinary industry is indeed having a substantial numbers of superior culinary talents. It can be observed that 20 percent of superior performers were identified in Instrument Testing I and 17 percent of superior performers in Instrument Testing II.

\subsection{Competency Profiling based on data from Instrument Testing I}

In the first instrument testing, there are three persons were identified as having a very good performance with a profile of culinary professionals who have knowledge of high degree of scientific cooking, possess entrepreneurial talents with characteristics as a daring person who are outspoken and a risk-taker. It was found that there are five items which are considered as the most difficult items. The first three items; "marketing for product promotion", "foresee new market", and "willingness to take risk in promoting new products" were categorized under entrepreneurial competency with a specific sub themes, which are the business acumen and opportunity alertness.

In line with these findings, Balasz [7] mentioned about the role of the chefs in France's great restaurant as creators, entrepreneurs and businessman. The chefs are being referred as rare species of individual [8]. The chefs involved in the business-related fragments of the operations and investment decisions, particularly in creating new products and services while at the same time working towards the creation of outstanding dining experiences. Furthermore, it was found that majority of the respondents easy to endorse an agreement towards their teamwork as the easiest item is "ability to work in teams". Working in the commercial hotels $^{\text {ee }}$ kitchen requires the participations of all kitchen crews. Most of the times, teamwork approach is transferred into daily work, therefore, working in teams has become their way of working, the culture of work [19].

The next difficult item for the respondents to endorse their agreement is "outspoken", which measure the personal quality in the aspect of extraversion. The finding is contradicted to the personality of those in the chefs ${ }^{\text {ee }}$ job which often associated with vocal, 
loud and flamboyant. Extravert chefs often associated with the celebrity chefs who involved working with the medias $[16,21]$ This might be due to the nature of working in the commercial kitchen, where the senior positions such as Head Chefs and Executive Chefs are the one who dominated the culinary cadre. Commonly, the extravert quality exhibits especially when the culinary professionals had reached the highest rank of chef's job. Their role as leaders contributes to the development of their personal quality [7, 13].

Accordingly, Rothmann and Coetzer [34, 35] mentioned that extraversion includes traits such as sociability, assertiveness, boldness. These qualities often displayed by those involved with jobs characterized by social interactions such as leaders and managers. Another difficult item is "knowledge of molecular cuisines", which measure science in culinary. Several authors $[20,38]$ highlighted on the importance of understanding meal sciences among todays' culinary professionals. Traditionally, emphasis was given only on the artistic element of the cuisines. Nowadays, culinary profession is considered as one profession that combine the arts and sciences of cooking where the concoction of arts and sciences is valuable and highly demanded for the current culinary world. With the current emergence of haute cuisine, the innovation processes of high level cooking brings new paradigm for science explorations in the cooking process [22].

Additionally, the highest logit value was demonstrated by a person who is an Executive Sous Chef in a 4-star hotel, aged between 36 to 45 years old whom has been working in culinary industry for more than 20 years. There are two people at lowest position in the scale. One of the person is a Chef de Partie who works in the culinary industry between 1115 years while another person is a Commis who have 6 to 10 years working experience. The findings are unexpected because lowest logit means that it is difficult for the person to endorse an agreement that reflects his or her ability to perform the competencies. It is expected that person with such period of working experience could demonstrate high level of competencies. Several authors shared their views regarding this matter. Although years of experience are required for culinary professionals, Baum [9] stipulated that experiential intelligence is one of the capabilities that are hardly possessed by individuals. Similarly, Ruokonen \& Saarenketo [36] asserted that the way workers capitalize the information gathered through their years of working will be determined by their experiential intelligence. Thus, the ability in manipulating experiences robustly for professional development is the key for successful career.

\subsection{Profiling based on data from Instrument Testing II}

There are two items which are considered as the most difficult items; SCI2 (know how to prepare molecular cuisine) and SCI1 (knowledge in cooking chemistry). Both items measure the technical competency from the aspect of culinary science. Culinary professionals are found to have difficulty in assenting that this statement reflects their competencies in culinary science. As mentioned earlier by Gustaffson [20], the acquiescent towards scientific culinary is important in understanding the meal sciences. Behind the cooking process, there are various chemical excitations that drive the transformation from raw ingredients into cooked meals. On the other hand, the easiest item is OPS7 (able to organize ingredients and equipment in readiness for food preparation - mise en place). This item is measuring technical competency in the kitchen operations. The finding is supported by the previous study by Zopiatis [45] which showed that technical culinary-specific competency is ranked as the highest level in competency acquisition and development.

The person who demonstrates the highest logit value is a male Executive Chef aged between 36 to 45 years old, with more than 20 years of experience. The person also has experience working in foreign country. Nevertheless, the person does not have MOSQ certification. It was found that the lowest logit position is a female Commis aged between 
18 to 25 years old. Her working experience is approximately five years and below. The finding is quite unanticipated because she has a MOSQ certification. For our local culinary professionals, the opportunity of working abroad is an added value because there is plentiful knowledge to be learned from foreign culture. International job relocation provides learning cosmoses where they learn new techniques and dishes. There is always a connection between travel and foods. Sullivan \& Arthur (2006) conceptualized on boundary less career as physical mobility (movement between jobs, institutions and countries) and psychological mobility (the perceptions of the capacity to make transitions).

There are careers which require both types of mobility where the authors put chef's profession as an example. The growing complexity in the career landscape requires chefs to work in several diverse restaurants where each new job contributes to a larger body of expertise and self-confidence. Within evaluation field, the issues of competency credentialing, licensure, certification is communal, with various implications came along with the process [2]. Additionally, Woolcock [41] and Audant [5] emphasized on the hands-on skills validation for culinary students through formal culinary education to advance their college completion. In the context of Malaysia, MOSQ certification for students, named as Malaysia Skills Certificate is offered by the culinary schools and institutions appointed as Accredited Centre for the Department of Skills Development (DSD), Ministry of Human Resources Malaysia. Some of the courses offered are food preparation/ chef training, bakery, pastry and food and beverages services (Department of Skills Development, 2015). However, normally the MOSQ certification for industrial workers is on voluntarily-basis. The connotations of certification among culinary professionals in Malaysia have yet to be achieved as efforts many efforts need to be done in order to improve the awareness of people in the industry regarding the MOSQ certification.

\section{Conclusion}

In designing $21^{\text {st }}$ century culinary competencies, competency profiles help organizations in providing directions for future requirements in the forthcoming decades. Implications derived are the need for more robust training schemes which equipped culinary professionals with relevant competencies to encounter complex high performance work settings in the modern contemporary culinary tourism.

The research is funded by Research University Grants (Potential Academic Staff Grant) of Universiti Teknologi Malaysia PY/2016/08211 (Q.J130000.2731.03K10)

\section{References}

1. Aguirre, J., \& Andrade, L. Students perception of the 21 st Century Chefs. Revista de Turismo Y Patrimonio Cultural, 11(2), 417-425, (2013).

2. Altschuld, J. W. Ceritification, Credentialing, Licensure, Competencies, And The Like: Issues Confronting The Field Of Evaluation. The Canadian Journal of Program Evaluation, 20(2), 157, (2005).

3. Anders Ericsson, K., Roring, R. W., \& Nandagopal, K. Giftedness and evidence for reproducibly superior performance: an account based on the expert performance framework. High Ability Studies, 18(1), 3-56, (2007).

4. Anders Ericsson, K., \& Towne, T. J. Expertise. Wiley Interdisciplinary Reviews: Cognitive Science, 1(3), 404-416, (2010).

5. Audant, A. B. Stackable credentials and career/college pathways in culinary arts at Kingsborough Community College, CUNY. Community College Journal of Research and Practice, 40(4), 299-309, (2016). 
6. Azrilah, A. A., Azlinah, M., Noor Habibah, A., Sohaimi, Z., Hamza, A. G., \& Mohd Saidfudin, M. Development of Rasch-based descriptive scale in profiling information professionals' competency. 2008 ISIT, 1-8, (2008).

7. Balazs, K. Some Like It Haute: Leadership Lessons From France' s Great Chefs, 30(2), 134-148, (2001).

8. Balazs, K. Take One Entrepreneur : The Recipe for Success of France' s Great Chefs, 20(3), 247-259, (2002).

9. Baum, T. Implications of hospitality and tourism labor marets for talent management strategies. International Journal of Contemporary Hospitality Management, 20(7), 720-729, (2008).

10. Birdir, K. Identified competencies of research chefs, (1998).

11. Birdir, K., \& Pearson, T. E. Research chefs ' competencies : a Delphi approach Research in brief Research chefs ' competencies: a Delphi approach. International Journal of Contemporary Hospitality Management Emerald Article, 12(3), 205-209, (2000).

12. Bissett, R. L., Cheng, M. S. H., \& Brannan, R. G. A Qualitative Assessment of Culinary Science Competencies Defined by the Research Chefs Association. Journal of Culinary Science \& Technology, 7(4), 285-293, (2010a).

13. Bloisi, W. Bullying and negative behaviour in commercial kitchens (Doctoral dissertation, The University of Manchester (United Kingdom), (2012).

14. Chung-Herrera, B. G., Enz, C. A., \& Lankau, M. J. A competencies model: Grooming future hospitality leaders. Cornell Hotel and Restaurant Administration Quarterly, 44(3), 17-25, (2003).

15. Deloitte, H. Global Human Resource. SHRM (9), (2013).

16. Ehrmann, T., Meiseberg, B., \& Ritz, C. Superstar effects in deluxe gastronomy-An empirical analysis of value creation in German quality restaurants. Kyklos, 62(4), 526541, (2009).

17. Fisher, W., Jr. Reliability, Separation, Strata Statistics. Rasch Measurement Transactions, 6(3), 238, (1992).

18. George, G. Philosophical foundations of workplace spirituality: A critical approach. Journal of business ethics, 78(4), 575-600, (2008).

19. Gröschl, S. Presumed incapable: Exploring the validity of negative judgments about persons with disabilities and their employability in hotel operations. Cornell Hospitality Quarterly, 54(2), 114-123.Gog and Joo, 2011), (2013).

20. Gustafsson, I. -B. Clinary arts and meal science - a new scientific research discipline. Food Service Technology, 4 (1), 9-20, (2004).

21. Henderson, J. C. Celebrity chefs: expanding empires. British Food Journal, 113(5), 613-624, (2011).

22. Hervas-oliver, J. L., de Miguel-Molina, B., \& Albors, J. How much important is the cluster effect? making sens of the firm's internal and meso (relational) resources to explain innovation. In DRUID Paper to presented at the Summer Conference, page $26 p,(2009)$.

23. Hu, M. L. Developing a core competency model of innovative culinary development. International Journal of Hospitality Management, 29(4), 582-590.

24. $\mathrm{Hu}, \mathrm{M}$. L. (2010b). Discovering culinary competency: An innovative approach. The Journal of Hospitality Leisure Sport and Tourism, 9(1), 65-72, (2010a).

25. Huang, Y.-L., \& Lin, C.-T. Management Trainee Core Competencies in the Hospitality Industry: Differences Between Managers and Scholars. Journal of Human Resources in Hospitality \& Tourism, 10(1), 1-13, (2010). 
26. Ko, W.-H. To evaluate the professional culinary competence of hospitality students. Journal of Culinary Science and Technology, 8(2-3), 136-146, (2010).

27. Koopmans, L., Coffeng, J. K., Bernaards, C. M., Boot, C. R. L., Hildebrandt, V. H., de Vet, H. C. W., \& van der Beek, A. J. Responsiveness of the individual work performance questionnaire. BMC Public Health, 14, 513, (2014).

28. Malhi, R. S. The hard truth about graduate employability and soft skills. ADEPT: Higher Education Leadership Research Bulletin, 3, 45-56, (2001).

29. Marrelli, A. F., Tondora, J., \& Hoge, M. A. Strategies for developing competency models. Administration and Policy in Mental Health and Mental Health Services Research, 32(5-6), 533-561, (2005).

30. Mokhtar, N. A., Poo, B. T., \& Salleh, N. H. M. Analisis keperluan tenaga manusia dalam industri pelancongan di Malaysia. PERKEM Proceedings, 7, 4-6, (2012).

31. Moustroufas, E., Stamelos, I., \& Angelis, L. Competency profiling for software engineers: literature review and a new model. In Proceedings of the 19th Panhellenic Conference on Informatics (pp. 235-240). ACM, (2015, October).

32. Orr, J. E., Sneltjes, C., \& Dai, G. The art and science of competency modeling. The Korn/Ferry Institute, 1-16, (2010).

33. Sanghi, S. The Handbook of Competency Mapping: Understanding, Designing and Implementing Competency Models in Organizations, 2nd Edition. SAGE Publications Pvt. Ltd., (2007).

34. Rothman, S., \& Coetzer, E. P. The relationship between personality dimensions and job satisfaction. Management Dynamics: Journal of the Southern African Institute for Management Scientists, 11(1), 29-42, (2002).

35. Rothmann, I., \& Cooper, C. Organizational and Work Psychology. Hodder Education (303), (2008).

36. Ruokonen, M., \& Saarenketo, S. The strategic orientations of rapidly internationalizing software companies. European Business Review, 21(1), 17-41, (2009).

37. Suhairom, N., Musta'amal, A. H., Ismail, S., Wahid, N. H. A., Hamid, M. Z. A., Ali, D. F., \& Jambari, H. A Qualitative Study of School-to-Work Transition Experience of New Culinary Graduates Towards a Sustainable Growth in the Profession. Advanced Science Letters, 23(8), 7407-7411, (2017).

38. Tittl, M. (2008). Careers in Food Science: Undergraduate to Professional, 267-275.

39. Viswesvaran, C., \& Ones, D. S. Perspectives on models of job performance. International Journal of Selection and Assessment, 8(4), 216-226, (2000).

40. Wang, W., Gao, J., \& Xie, X. A study to develop a competency model for Chinese EHS managers. Frontiers of Business Research in China, 5(4), 580-596, (2011).

41. Woolcock, C., \& Ferguson, P. Paper code: 2265, 1-11, (2006).

42. Workitect, I. Competencies and Competitiveness. Www.workitect.com, 1-6, (2006).

43. Wright, B. D., \& Masters, G. N. Number of person or item strata. Rasch Measurement Transactions, 16(3), 888, (2002).

44. Zakaria, M. A., Wahab, S. H. A., \& Jasmi, M. A. Culinary art education: A demanding profession in culinary tourism for Malaysian's New Economy Niche. In Proceeding of the 1st UPI International Conference on Technical and Vocational Education and Training, (2010, November).

45. Zopiatis, A. Is it art or science? Chef's competencies for success. International Journal of Hospitality Management, 29(3), 459-467, (2010). 